\title{
ANAP

\section{AS RELAÇÕES ENTRE OS SOLOS O USO E A SUSCETIBILIDADE A EROSÃO NO MUNICÍPIO DE IGUARAÇU - PR}

\author{
Lilian Yumi Toda ${ }^{2}$
}

Maria Cleide Baldo ${ }^{3}$

Francieli Sant'ana Marcatto ${ }^{4}$

\begin{abstract}
RESUMO
O município de Iguaraçu está localizado na região Norte Central Paranaense numa área de contato entre 0 arenito e 0 basalto, originando solos com características morfológicas, químicas, físicas e mineralógicas bem diferenciadas. O objetivo desse trabalho é caracterizar 0 relevo a declividade a geologia e os solos, bem como fazer a análise das relações desses aspectos físicos em conjunto com o uso da terra e a suscetibilidade à erosão, visando um raciocínio de síntese para delimitação de unidades de paisagem. Concluiu-se que o cultivo da cana-de-açúcar e criação de aves está exclusivamente disposto em solos de textura média com fertilidade baixa e de suscetibilidade à erosão moderada à forte. A pastagem está dispersa, em solos de textura média, de baixa fertilidade e em solos rasos ambos com suscetibilidade à erosão que varia de moderada/forte à forte. A lavoura temporária predomina nos solos de textura argilosa, de alta fertilidade com suscetibilidade ligeira a moderada.
\end{abstract}

PALAVRAS-CHAVE: Iguaraçu-PR. Solos. Suscetibilidade à erosão. Uso do solo.

\footnotetext{
${ }_{2}^{1}$ Prof. Dr. em Geografia - Universidade Estadual de Maringá - hesilveira70@hotmail.com.

2 Licenciada e bacharel em Geografia pela Universidade Estadual de Maringá lyt_toda2@hotmail.com

Prof. Dra. em Geografia da Universidade Tecnológica Federal do Paranámcbaldo33@hotmail.com

${ }^{4}$ Mestranda em Geografia, Universidade Estadual de Maringá, fran_marcatto@hotmail.com
} 


\title{
ANAP

\section{REVISTA C IENTÍF I C A 2015}

\author{
THE RELATIONS BETWEEN THE SOIL USE AND THE \\ SUSCEPTIBILITY EROSION IN IGUARAÇU CITY - PR
}

\begin{abstract}
The municipality of Iguaraçu is located in North Central region Paranaense in a contact area between the sandstone and basalt, yielding soils with morphological, chemical, physical and mineralogical well differentiated. The aim of this work is to characterize the relief slope geology and soils, as well as make the analysis of the relationship of these physical aspects together with land use and susceptibility to erosion seeking a summary rationale for delimitation of landscape units. It was concluded that the cultivation of cane sugar and poultry is exclusively arranged in medium textured soils with low fertility and susceptibility to erosion moderate to strong. The pasture is dispersed in medium textured soils of low fertility and shallow soils both with susceptibility to erosion ranging from moderate/strong to strong. The seasonal crop predominates in clayey soils, high fertility with mild to moderate susceptibility.
\end{abstract}

KEYWORDS: Iguaraçu-PR. Soils. Susceptibility to erosion. Land use.

\section{RELACIONES ENTRE EL USO DEL SUELO Y SUSCEPTIBILIDAD EROSIÓN EN UNA CIUDAD DE IGUARAÇU - PR}

\begin{abstract}
RESUMEN
El municipio de lguaraçu se encuentra en el norte de la región central Paranaense en un área de contacto entre la arenisca y basalto, produciendo suelos con características morfológicas, químicas, físicas y mineralógicas bien diferenciado. El objetivo de este trabajo es caracterizar la geología pendiente relieve y los suelos, así como hacer el análisis de la relación de estos aspectos físicos junto con el uso del suelo y la susceptibilidad a la erosión que buscan una justificación resumen para la delimitación de las unidades de paisaje. Se concluyó que el cultivo de la caña de azúcar y aves de corral está dispuesto exclusivamente en suelos de textura media con baja fertilidad y la susceptibilidad a la erosión de moderada a fuerte. El pasto se dispersa en suelos de textura mediana de baja fertilidad y suelos poco profundos, tanto con la susceptibilidad a la erosión de moderada / fuerte a fuerte. La cosecha estacional predomina en los suelos arcillosos, alta fertilidad con leve a moderada susceptibilidad.
\end{abstract}

PALABRAS-CLAVE: Iguaraçu-PR. Suelos. Susceptibilidad a la erosión. El uso del suelo.

\section{INTRODUÇÃO}

Os impactos negativos advindos do uso irracional do solo tem se tornado um problema cada vez mais crescente na sociedade atual, sobretudo em regiões onde a economia está baseada na agricultura. 


\section{ANAP Brasil \\ ISSN 1904-3240 \\ V. 8, n. 12}

\section{REVISTA CIENTÍFICA 2015}

O solo é parte integrante da paisagem e sua distribuição esta condicionada pela ação combinada dos fatores de formação, tais como o relevo, o material de origem, o clima e o tempo. O conhecimento do solo é essencial para elucidar o fenômeno de erosão e assoreamento, cuja compreensão é primordial ao planejamento, já que seu efeito contribui na degradação ambiental e afeta diretamente atividades econômicas.

A erosão, um dos fenômenos causadores da degradação dos solos, vem sendo acelerado pelas ações antrópicas como o desmatamento, ausência de métodos conservacionistas do solo na agricultura e nas obras urbanas mal planejadas.

Desta forma, as questões relacionadas aos processos de degradação dos solos têm sido amplamente discutidas no Estado do Paraná, principalmente em regiões onde o solo é mais susceptível à erosão, como no noroeste do Estado.

O município de Iguaraçu está localizado na região norte central do Estado do Paraná, em área de contato geológico arenito-basalto, originando classes de solos com características morfológicas, químicas, físicas e mineralógicas bem diferenciadas e, portanto, propiciando diversificação na distribuição e uso, assim como a suscetibilidade à erosão destes solos ao longo das vertentes.

O presente trabalho tem como objetivo caracterizar o relevo, a declividade, a geologia e os solos, bem como fazer a análise das relações desses aspectos físicos em conjunto com o uso da terra e a suscetibilidade à erosão visando um raciocínio de síntese para delimitação de unidades de paisagem no município de Iguaraçu - PR.

\section{MATERIAL E MÉTODOS}

\subsection{Material}




\section{ANAP Brasil \\ ISSN 1904-3240 \\ v. 8, n. 12}

\section{REVISTA CIENTÍFICA 2015}

O município de Iguaraçu está localizado no Terceiro Planalto ou Planalto de Guarapuava, na mesorregião Norte Central do Estado do Paraná, mais especificamente na microrregião de Astorga. Encontra-se entre as latitudes de $23^{\circ} 16^{\prime} 26^{\prime \prime}$ a $23^{\circ} 13^{\prime} 24^{\prime \prime}$ Sul, e as longitudes de $51^{\circ} 56^{\prime} 34^{\prime \prime}$ a $51^{\circ}$ 44' 05" Oeste (Figura 1).

A estrutura geológica é composta por rochas vulcânicas básicas (basalto) da Formação Serra Geral (Grupo São Bento), de idade TriássicoJurássico e rochas sedimentares arenosas (arenitos) das Formações Adamantina, Santo Anastácio e Caiuá. Há ainda, a presença de sedimentos argilosos recentes nas margens do rio Pirapó (MINEROPAR, 2001).

\subsection{Método}

A escolha da área de estudo se deve a diversidade litológica, pedológica e consequentemente de uso e ocupação do solo e de suscetibilidade à erosão.

Para a elaboração dos produtos cartográficos foi utilizado o software Spring versão 5.2.3. A carta de geologia do Estado do Paraná foi disponibilizada gratuitamente pelo sítio eletrônico da MINEROPAR (http://www.mineropar.pr.gov.br/), folha de Londrina, SF.22-Y-D, escala 1:250.000, formato *.shp, ano de 2005. A carta de solos do Estado do Paraná foi adquirida no sítio eletrônico da Embrapa (http://mapoteca.cnps.embrapa.br/2, sendo ela, Folha SF.22-Y-D, MIR - 496, escala 1:250.000, formato *.shp, ano de 2008.

Para elaborar a carta com as classes de relevo e declividade foi necessário utilizar as imagens SRTM (Shuttle Radar Topography Mission). Para os intervalos das classes de declividade foram utilizadas as determinações estabelecidas no Manual técnico de pedologia (IBGE, 2006). A carta de cobertura vegetal e uso do solo foi elaborada através da imagem de satélite Landsat5, sensor TM, bandas 5, 4 e 3 (RGB), orbita 22, ponto 76, com 


\section{ANAP Brasil \\ ISSN 1904-3240 \\ V. 8, n. 12}

\section{REVISTA CIENTÍF I CA}

resolução espacial de 30 metros $\left(1 P I X E L=900 \mathrm{~m}^{2}\right)$, com data de passagem em 4/nov/2011 obtidas via sítio eletrônico do Instituto de Pesquisa Espaciais (INPE, 2013), no formato Geotiff. Após todos os procedimentos operacionais foi possível identificar os diferentes tipos de cobertura vegetal e uso da terra mais representativos para o município, como as florestas densas, pastagens, lavouras permanentes, lavoura de cana-de-açúcar e áreas urbanas. Esta categorização foi baseada no Sistema de classificação para cobertura de uso da terra, abordada pelo IBGE (2006).

Para a realização da carta de suscetibilidade à erosão foram adotados os critérios estabelecidos pela EMBRAPA (1988).

Após a elaboração das cartas temáticas contendo as principais classes de solos, formações geológicas, declividade, uso e ocupação da terra e suscetibilidade à erosão, pode-se delimitar as unidades de paisagem identificadas por variáveis físicas e pela dinâmica do uso e ocupação do solo. Foram escolhidos ainda quatro seguimentos de áreas consideradas representativas no município, para elaboração dos perfis geoambientais, que foram finalizados no Software Corel Draw X6.

A última etapa consistiu na análise integrada através da correlação dos dados obtidos tanto nos mapas temáticos quanto nos perfis geoambientais, buscando um raciocínio de síntese que confirmaria a delimitação das unidades de paisagem.

\section{RESULTADO E DISCUSSÃO}

$\mathrm{Na}$ porção norte do município de Iguaraçu predominam as rochas sedimentares do Grupo Bauru, constituídas pelas Formações Adamantina $(0,4 \%)$, Santo Anastácio (2\%) e Caiuá (38\%), que juntas ocupam $40,4 \%$ da área do território de Iguaraçu (Figura $1 \mathrm{~A}$ ).

Ao sul do município encontra-se o basalto, que ocupa $57 \%$ da área total. Nesta mesma porção, em sua extremidade, nas proximidades do leito do 


\section{ANAP

\section{REVISTA CIENTÍFICA}

rio Pirapó, cerca de $2,6 \%$ da área é recoberta por sedimentos recentes não consolidados, com matriz argilosa, denominados como depósitos de talus (Figura 1A).

A área de estudo apresenta quatro classes de solos, o Neossolo Regolítico, o Argissolo Vermelho, o Nitossolo Vermelho e o Latossolo Vermelho (Figura 1B). O Neossolo Regolítico eutrófico textura argilosa, presente em $5 \%$ da área, é derivado de rocha vulcânica do grupo São Bento, possui textura argilosa e está presente na área mais dissecada do município, extremidade sul, onde o relevo varia de ondulado a forte ondulado. São solos de alta fertilidade, pouco evoluídos, com profundidade de até $50 \mathrm{~cm}$ e com horizonte $A$ sobrejacente a horizonte $\mathrm{C}$ ou $\mathrm{Cr}$ e/ou de contato lítico (EMBRAPA, 2006; IBGE 2007).

Figura 1: Geologia (A) Classes de solos (B) do município de Iguaraçu-PR.

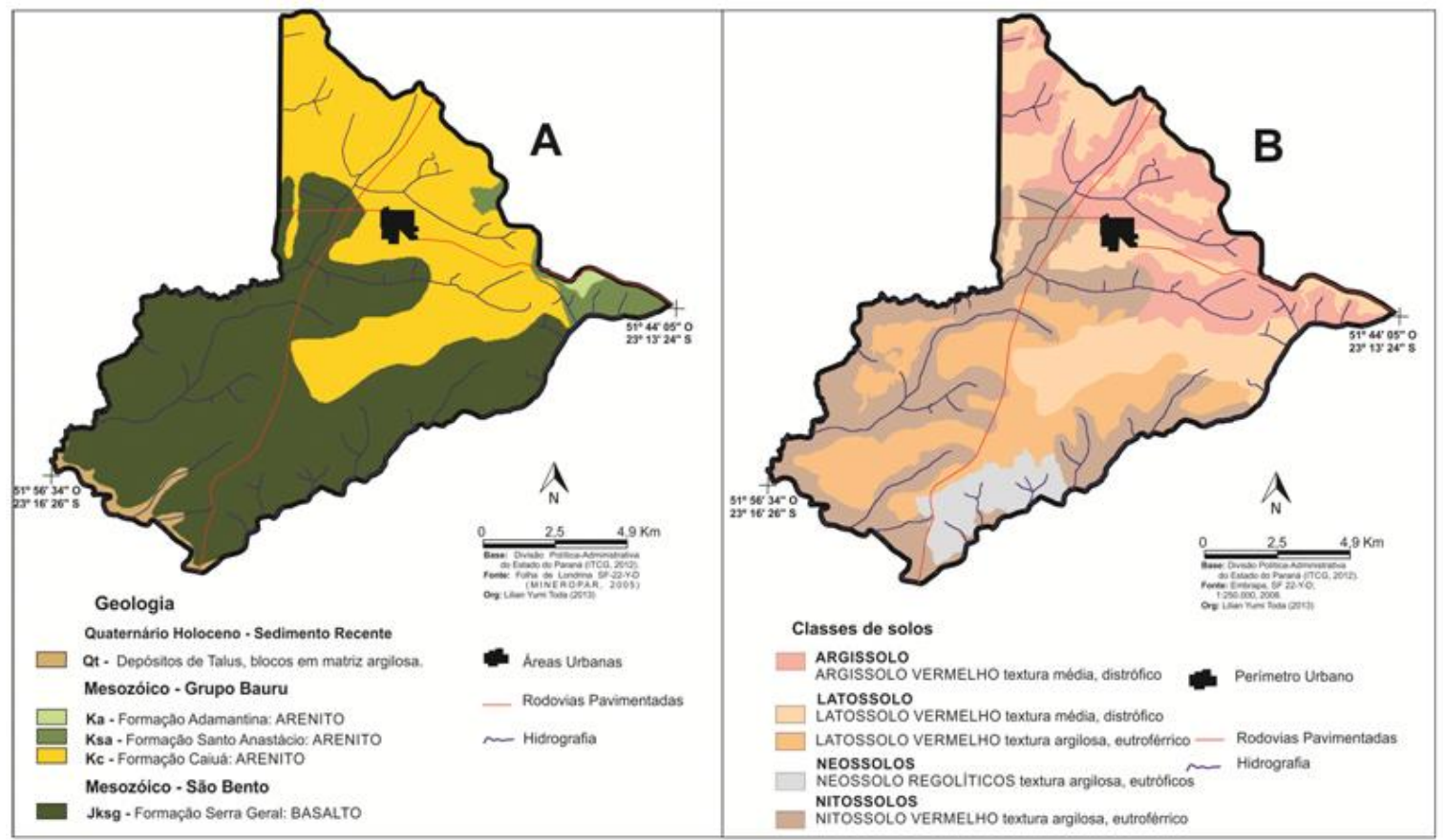

Fonte: Os autores, (2015)

Argissolo Vermelho distrófico textura média, presente em $20 \%$ da área, é derivado de rochas sedimentares arenosas do grupo Bauru, ocupa 


\section{ANAP Brasil ISSN 1904-3240 v. 8, n. 12}

\section{REVISTA CIENTÍFICA 2015}

áreas de relevo suave ondulado, ondulado e forte ondulado ao norte e nordeste do município. Estes solos são de baixa fertilidade, profundos, com sequência de horizontes $A, E, B t$ e $C$, reconhecidos principalmente pelo gradiente textural entre os horizontes $A$ e $B$, onde o horizonte superficial $A$ é arenoso e 0 subsuperficial Bt de textura média (IAPAR 1994, 1988).

O Nitossolo Vermelho eutroférrico textura argilosa, presente em 34\% da área é derivado de rochas basálticas do Grupo São Bento. Encontra-se localizado em relevo suave ondulado, ondulado e forte ondulado, no oeste, sudeste e ao sul do município. São solos de alta fertilidade, profundos, caracterizados pela presença de um horizonte $B$ nítico subsuperficial com moderado ou forte desenvolvimento estrutural do tipo prismático ou blocos angulares a subangulares com a superfície dos agregados reluzentes, relacionados à cerosidade. Tem textura argilosa e a diferença textural entre 0 horizonte A e B nítico é inexpressiva (IBGE, 2007; EMBRAPA, 2006).

O Latossolo Vermelho distrófico textura média foi encontrado em áreas de topo, em relevo plano e suave ondulado onde há a presença de rochas sedimentares arenosas (Formação Caiuá, Santo Anastácio e Adamantina). Esta classe de solo está presente em $20 \%$ do total da área, na porção norte de Iguaraçu, compreendendo também parte da porção nordeste e central. São solos de baixa fertilidade, profundos e de grande homogeneidade morfológica ao longo do perfil. Possui sequência de horizontes $A, B, C$, sendo a espessura $A+B$ superior a três metros, são ainda, muito porosos e friáveis (EMBRAPA, 2006; IBGE, 2007; IAPAR, 1988).

Em direção à porção sul, oeste, sudeste e central, encontra-se 0 Latossolo Vermelho eutroférrico textura argilosa, formado pela alteração do basalto. Esta classe de solo encontra-se em relevo plano e suave ondulado e representa $21 \%$ do território de Iguaraçu. É um solo de boa fertilidade, muito profundo, com pequena diferenciação morfológica entre os horizontes. Possui uma distribuição de argila relativamente uniforme ao longo do perfil e elevado 


\section{ANAP Brasil \\ ISSN 1904-3240 \\ v. 8, n. 12}

\section{REVISTA C IENTÍF I C A 2015}

grau de floculação das argilas, é muito poroso e muito friável (EMBRAPA, 2006; IBGE, 2007; IAPAR, 1988).

As classes de relevo predominantes são: suave ondulado (declividade de 3 a 8\%) e ondulado (declividade entre 8 a 20\%), que correspondem a 58\% e $30 \%$, respectivamente, do total da área do município. Já o relevo plano (declividade de 0 a $3 \%$ ) representa apenas $11,2 \%$ e o relevo forte ondulado (declividade entre 20 a 45\%) soma 0,8\%, localizando-se na extremidade sul do município.

$\mathrm{Na}$ porção norte e leste, predomina o relevo suave ondulado e ondulado, enquanto na porção central, oeste e sul, variam do plano ao suave ondulado. A classe ondulado é observado principalmente nas áreas próximas aos cursos d'água (Figura 2A).

As classes de suscetibilidade à erosão observadas no município foram ligeiro, moderado, moderado/forte, forte e muito forte (Figura 2B).

Foi verificado que $26 \%$ da área são compreendidas como classe de suscetibilidade à erosão denominada como ligeira, que foi observada em áreas dominadas pelo Nitossolo Vermelho eutroférrico textura argilosa, com declividade entre $0-3 \%$ (plano) e pelo Latossolo Vermelho eutroférrico textura argilosa entre as declividades de $0-8 \%$ (plano e suave ondulado) (Figuras 1B, $2 \mathrm{~A}$ e $2 \mathrm{~B}$ ). Nessas classes de suscetibilidade, quando os solos são usados para agricultura são reconhecíveis apenas ligeiros fenômenos erosivos (EMBRAPA, 1988). 


\section{ANAP

\section{REVISTA C IENTÍF I C A 2015}

Figura 2: Classes de declividade e relevo (A) Classes de susceptibilidade à erosão (B).

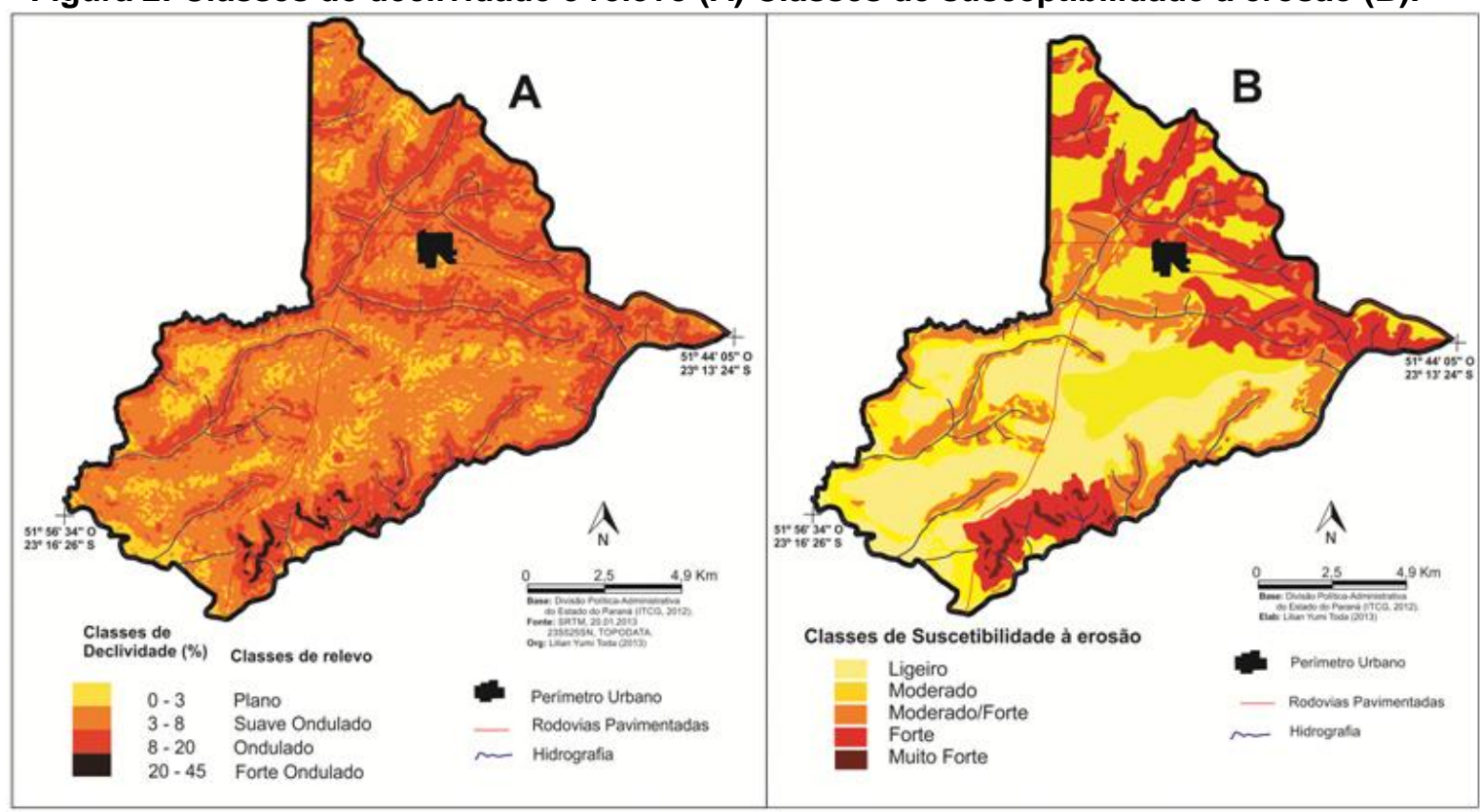

Fonte: Os autores, (2015)

A classe moderada corresponde a $27,3 \%$ da área de pesquisa e foi encontrada em declives de 0 a $8 \%$ (plano e suave ondulado) para o Latossolo Vermelho distrófico textura média e 3 a $8 \%$ (suave ondulado) para Nitossolo Vermelho eutroférrico textura argilosa (Figuras 1B, 2A e 2B). A erosão é reconhecível por fenômenos que são moderados no início e que se agravam rapidamente devido ao declive e a classe de solo dessas áreas, principalmente quando são usadas para a agricultura, sem o manejo adequado (EMBRAPA, 1988).

Pode-se observar que $21,4 \%$ da área têm como classe de suscetibilidade à erosão a moderado/forte e compreendem os setores ocupados com o Argissolo Vermelho distrófico textura média, com declividades entre 3 a $8 \%$ (suave ondulado) e Nitossolo Vermelho eutroférrico textura argilosa, com declividade entre 8 a 20\% (ondulado) (Figuras 2B, 3A e 3B). Nesses solos, logo que sua vegetação é removida, manifestam-se sinais de erosão que logo se agravam transformando-se em voçorocas, exigindo medidas de controle de erosão rigorosas (EMBRAPA, 1988). 


\section{ANAP $B_{\text {rasil }}$ \\ ISSN 1904-3240 \\ V. 8, n. 12}

\section{REVISTA CIENTÍFICA 2015}

A classe de suscetibilidade à erosão forte representa $25,4 \%$ do município e foi observada em áreas de Argissolo Vermelho distrófico textura média e no Neossolo Regolítico eutrófico textura argilosa, com declividades entre 8 a 20\% (ondulado). Os solos com essa suscetibilidade quando usados para agricultura, são reconhecíveis processos erosivos como sulcos, ravinas e voçorocas em grande parte de sua área (EMBRAPA, 1988).

As áreas com suscetibilidade à erosão muito forte correspondem a $0,8 \%$ do total e encontram-se nos locais com presença do Neossolo Regolítico textura argilosa, onde a declividade varia de 20 a $45 \%$ (relevo forte ondulado) conforme pode-se observar através das Figuras 1B, 2A e 2B. Devido à forte declividade e pouca espessura, esses solos tornam-se fortemente suscetíveis à erosão quando usados para agricultura ou para a pecuária.

Foi observado que o uso do solo é bem variado, com a presença de lavoura temporária, pastagem, cana-de-açúcar, florestas, barracões para criação de avicultura e área urbana. Contudo, esse mapeamento demonstra que a predominância do uso está entre a lavoura temporária (soja, milho e trigo), que representam $60 \%$ da área municipal, seguida pela pastagem, com $21 \%, 10 \%$ por lavoura de cana-de-açúcar, $6 \%$ para a floresta, $1 \%$ por barracões de criação de aves (54 barracões) e $2 \%$ identificado como a área urbana (Figura 3). 


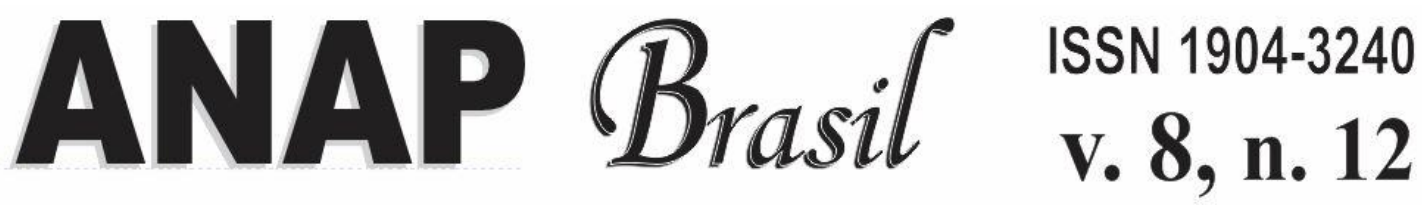

\section{REVISTA CIENTÍFICA 2015}

Figura 3: Cobertura vegetal e uso da terra

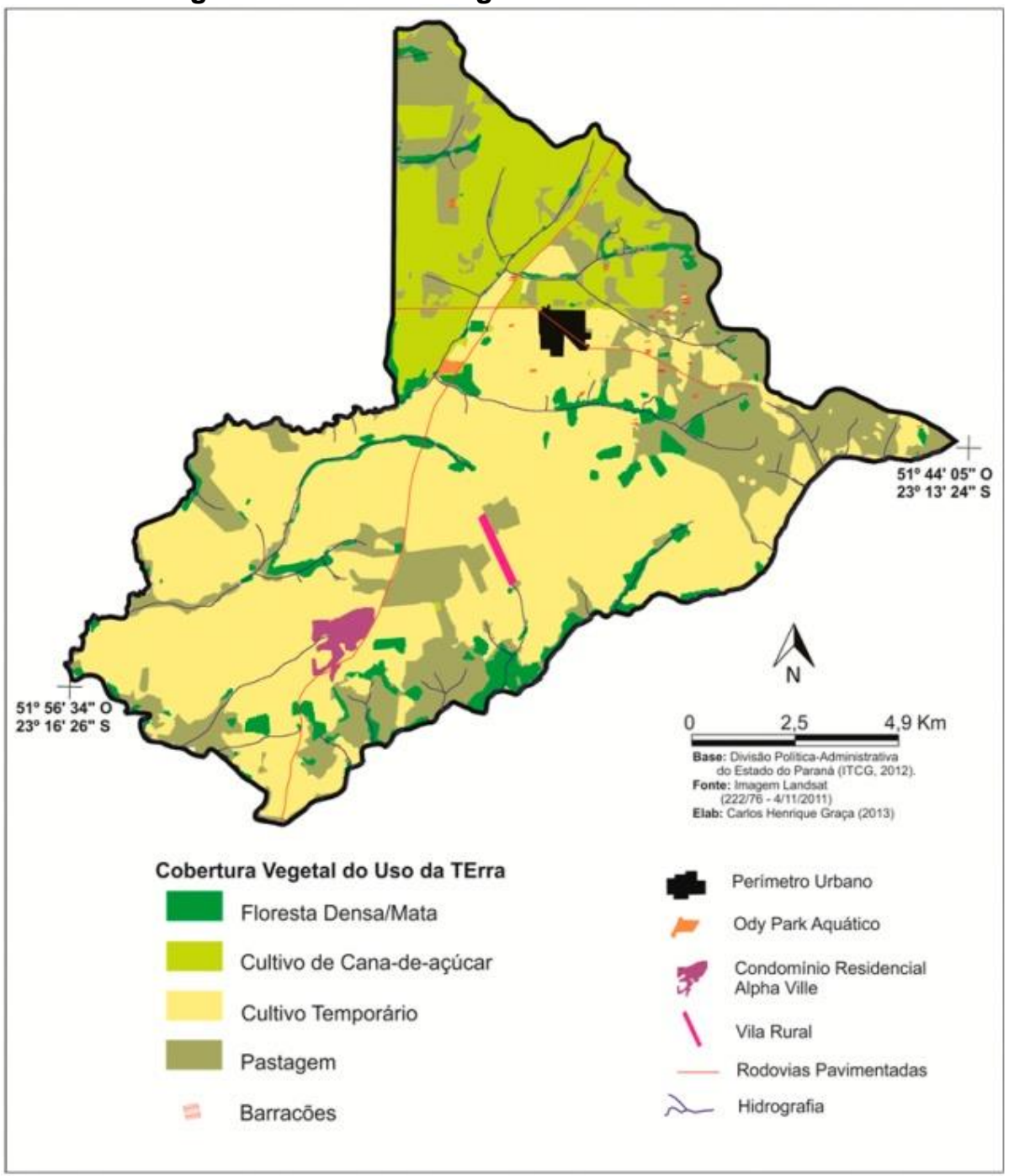

Fonte: Google Earth, 2012.

As lavouras temporárias mecanizadas como a soja, o milho e o trigo ocupam $60 \%$ do município (Figura 3 ). Essas lavouras temporárias ou sazonais se estabelecem preferencialmente nas áreas de solos de textura argilosa, com relevo plano a suave ondulado, onde a suscetibilidade à erosão predominante é ligeira a moderada, conforme mostram as Figuras 1B, 2A, 4 e na unidade de paisagem I, da Figura 8. Estes solos são considerados ideais para a agricultura, pois permite diversos usos sem a necessidade de exigências rigorosas de conservação do solo. 


\section{ANAP

Figura 4: Perfil geoambiental representativo das áreas de solos de textura argilosa cultivados com lavouras temporárias.

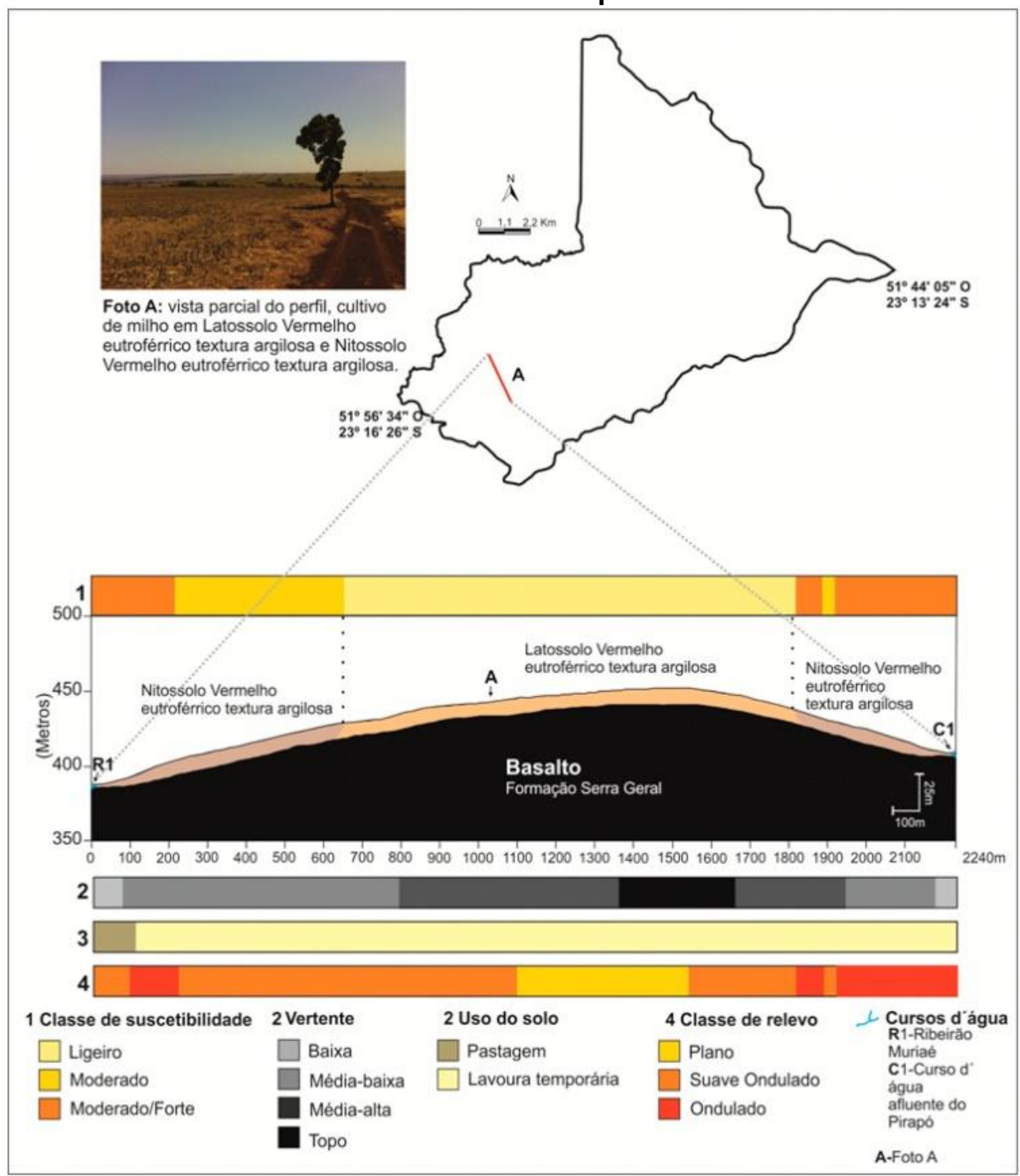

Fonte: Os autores, (2015)

Entretanto, as áreas com presença de Latossolo Vermelho textura média, em contato com o Nitossolo Vermelho de textura argilosa e o Latossolo Vermelho textura argilosa, também são utilizadas para o cultivo destas lavouras, embora sejam observadas algumas áreas com pastagem (Figuras 1B, 3, 5 e 8). Segundo as informações adquiridas junto a EMATER de Iguaraçu (2013), as propriedades ocupadas por lavouras de soja, milho e trigo vêm 


\section{ANAP

\section{REVISTA CIENTÍFICA}

avançando em solos de textura média (anteriormente ocupadas por pastagem) para cobrir a demanda do mercado, em especial aquelas propriedades que estão próximas das áreas de contato geológico (zona de transição), onde o agricultor encontra na sua propriedade os solos formados do arenito na parte alta da propriedade (topo) sob o Latossolo Vermelho de textura média, e na média/alta vertente o Latossolo Vermelho textura argilosa. O Nitossolo Vermelho de textura argilosa encontra-se na média/baixa a baixa vertente. A suscetibilidade nessas áreas varia de ligeiro, moderado a moderado/forte (Figura 5 e na unidade de paisagem II da Figura 8).

Figura 5: Perfil geoambiental representativo das áreas de transição de solos de textura argilosa e média.

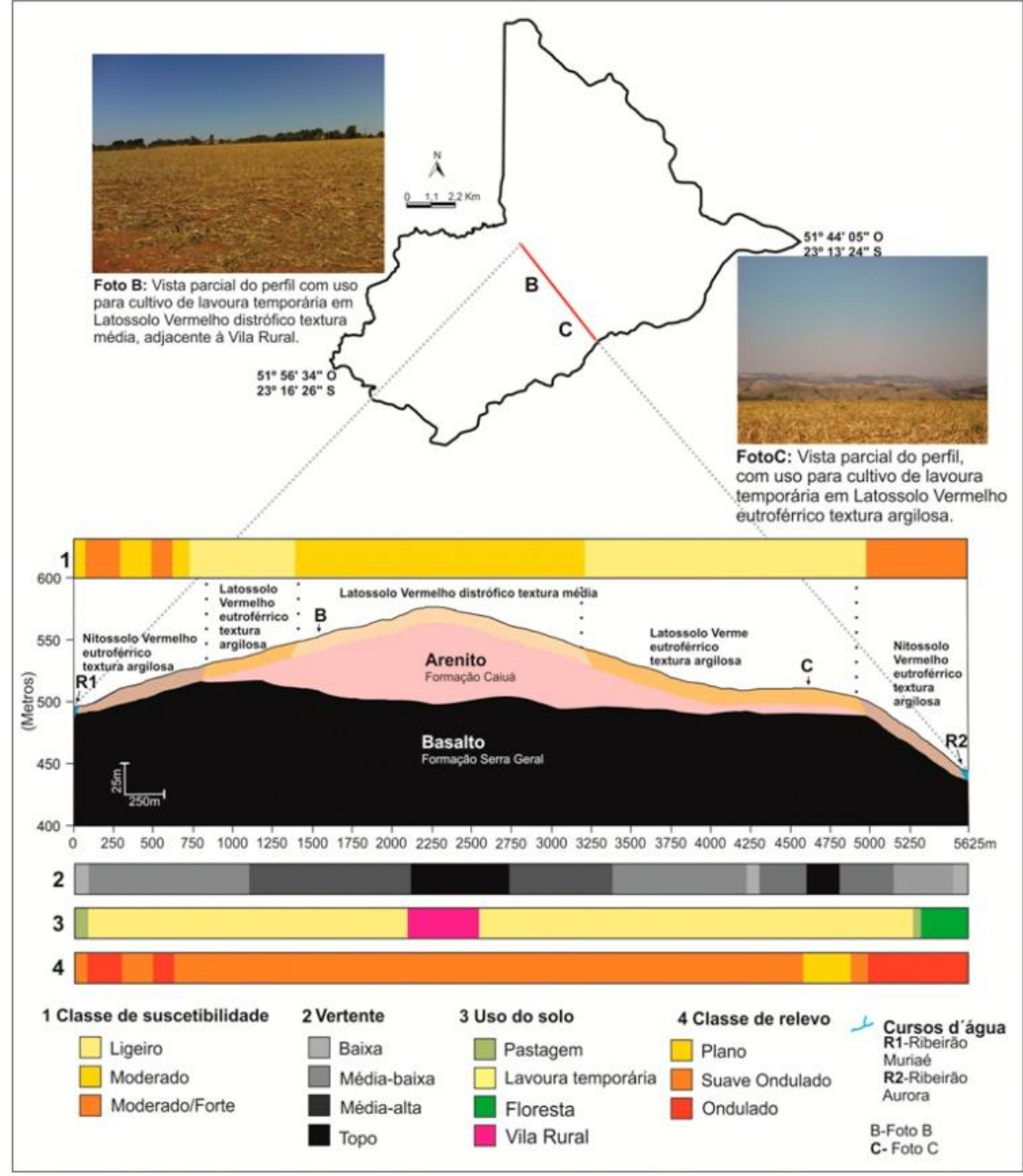

Fonte: Os autores, (2015) 


\section{ANAP

A pastagem ocupa $21 \%$ do território de Iguaraçu e encontra-se nas áreas com relevo suave ondulado e ondulado sob Argissolo Vermelho distrófico textura média e Latossolo Vermelho textura média predominantemente, ou sobre o Neossolo Regolítico eutrófico textura argilosa em relevo forte ondulado, mas também foram observadas pequenas manchas de pastagens em outros tipos de solos, em diversas classes de relevo (Figura 1B, 3 e 6) e unidades de paisagem (Unidade III e IV da Figura 8).

Figura 6: Perfil geoambiental representativo das áreas utilizadas com pastagem.

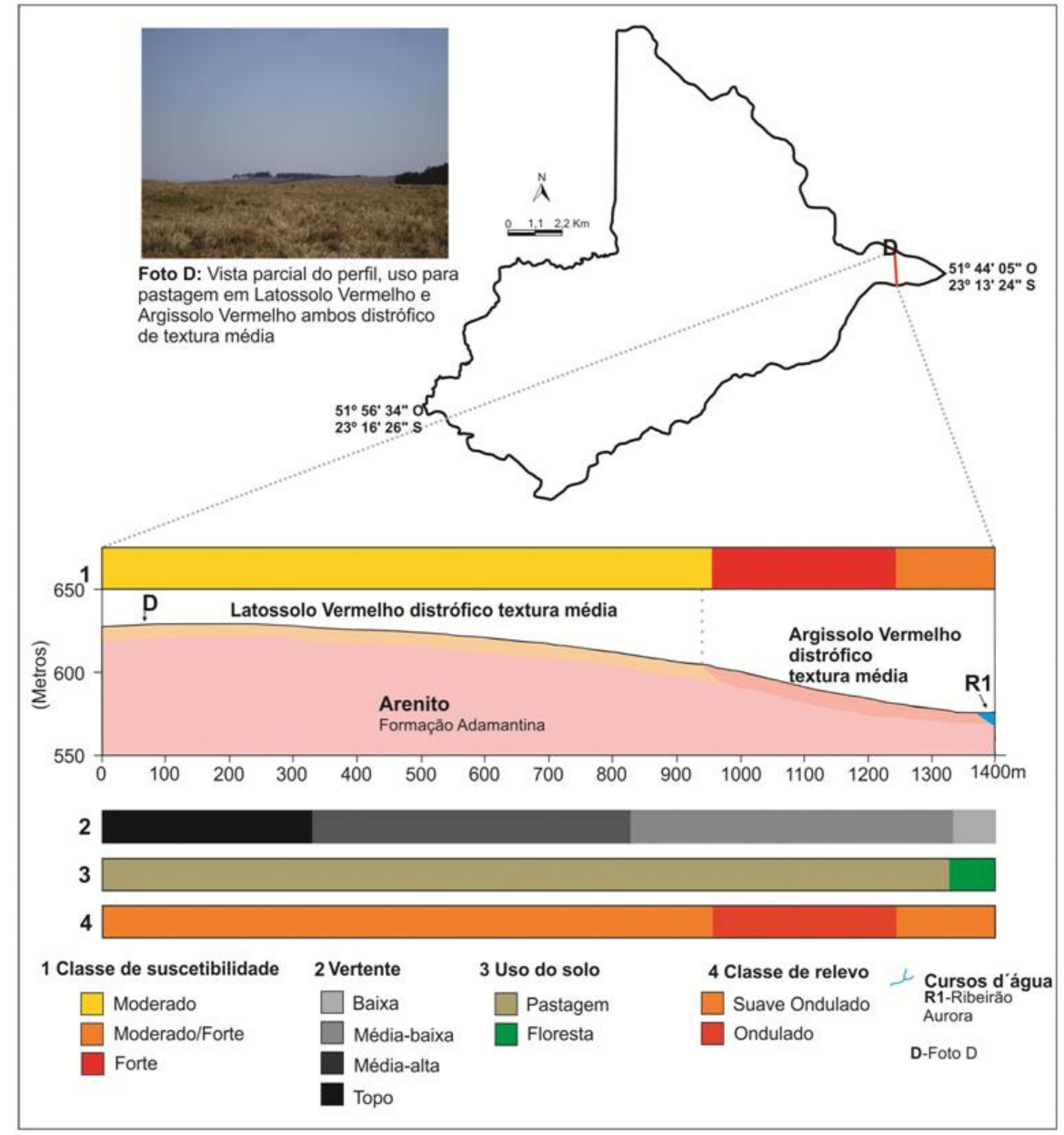

Fonte: Os autores, (2015) 


\section{ANAP

\section{REVISTA CIENTÍFICA}

A cana-de-açúcar está presente em 10\% do município e ocupa as porções de relevo plano, suave ondulado e ondulado (Figura 2A), exclusivamente em solos de textura média (Latossolo Vermelho e Argissolo Vermelho) onde a suscetibilidade à erosão predominante é a moderada, moderada/forte e forte, respectivamente (Figura 1B e 2B). Segundo a EMATER de Iguaraçu, são grandes as propriedades que foram arrendadas para as usinas Alto Alegre e Usina Cooperativa Nova Produtiva para o cultivo dessa cultura (Figura 7 e unidade de paisagem IV da Figura 8).

Também nessas localidades há um crescimento no número de barracões para criação de aves (1\% do território). De acordo com informações obtidas pela EMATER de Iguaraçu, são 35 propriedades envolvidas com a avicultura de corte, que resulta na capacidade instalada para alojar 1.613.500 cabeças.

Essa atividade econômica contribui como uma nova fonte de renda para os proprietários que se encontram em áreas de solos com menor capacidade produtiva, que são os de textura média. 


\section{ANAP \\ Brasil \\ ISSN 1904-3240 \\ V. 8, n. 12}

\section{REVISTA CIENTÍF I CA}

Figura 7: Perfil geoambiental representativo das áreas ocupadas com cana-deaçúcar.

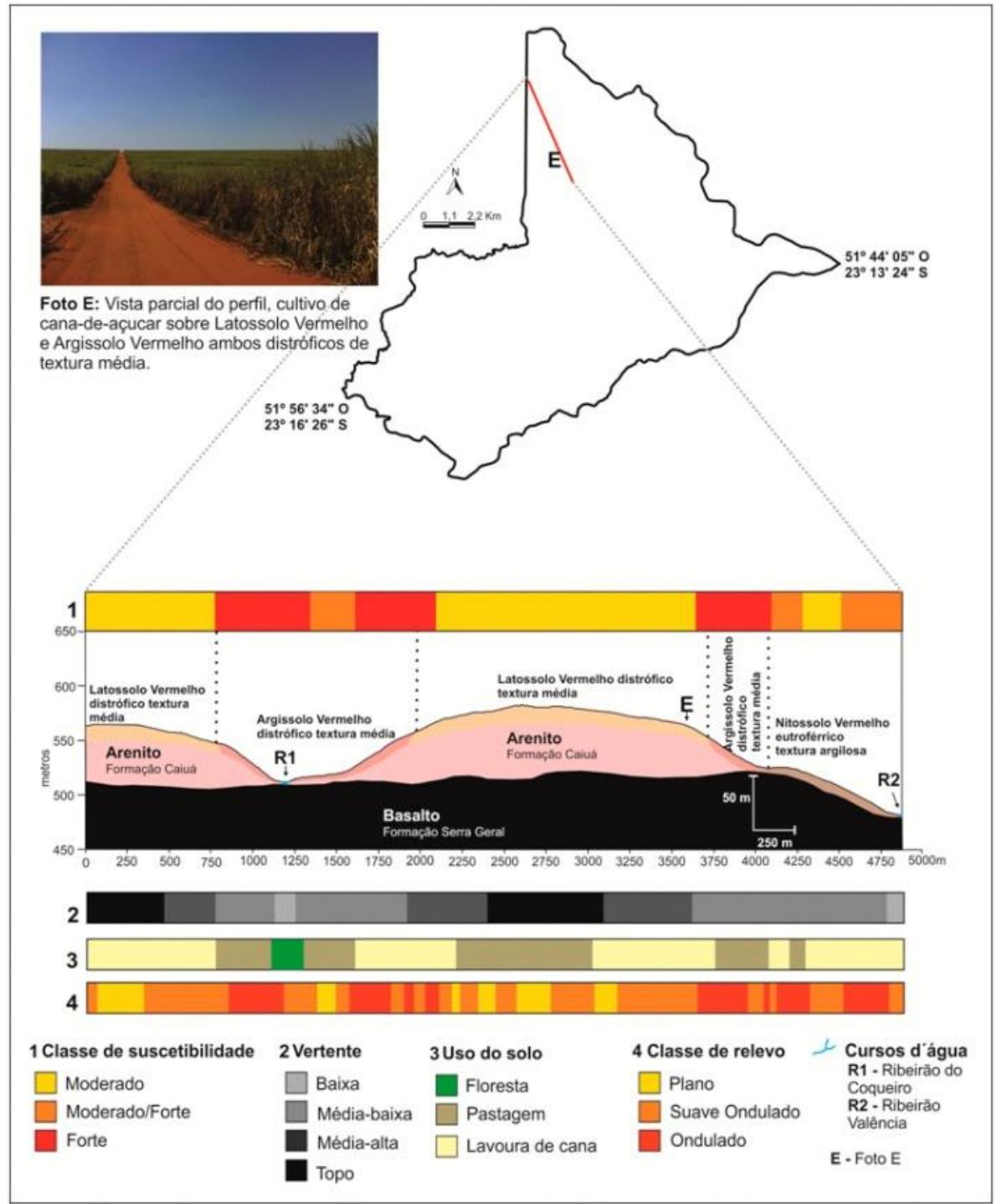

Fonte: Os autores, (2015)

O perímetro urbano de Iguaraçu encontra-se no centro norte do municípo e o condomínio residencial Alphaville, ao sul, mais próximo dos limites do município de Maringá, considerado como um ponto estratégico para a especulação de novos mercados imobiliários, atualmente esse tipo de uso ocupa $2 \%$ do município. 


\section{ANAP \\ Brasil \\ ISSN 1904-3240 \\ v. 8, n. 12}

\section{REVISTA CIENTÍF I CA}

As florestas estão preferencialmente as margens dos cursos d'água e em áreas de relevo muito dissecado e correspondem a apenas 6\% (Figura 3).

Através da Figura 8 é possível visualizar espacialmente com maior detalhe as 4 unidades de paisagens, com as principais características físicas e socioambientais no município de Iguaraçu.

Figura 8: Mapa síntese das unidades de paisagem no município de Iguaraçu-PR.

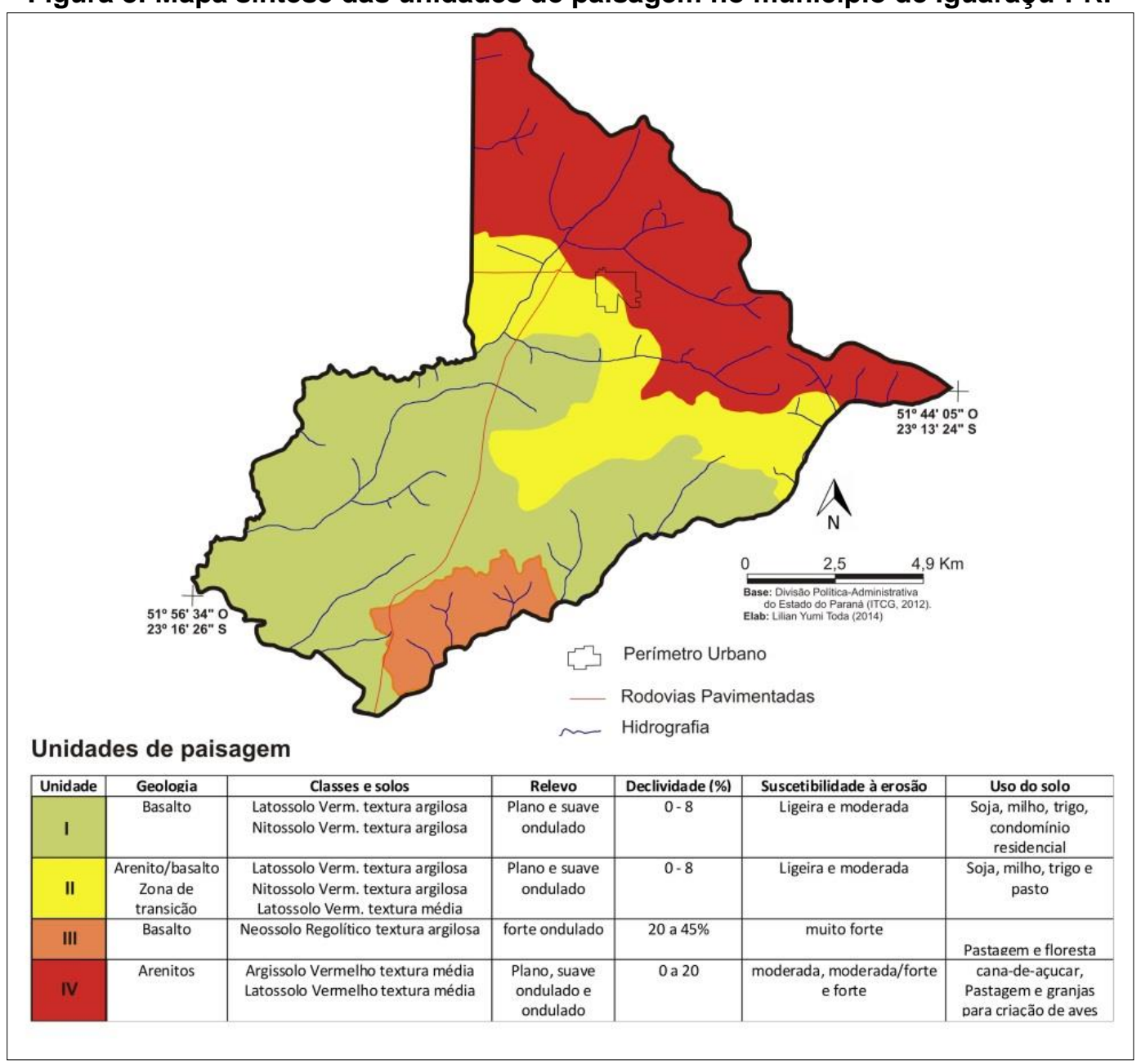

Fonte: Os autores, (2015)

\section{Conclusões}

A análise integrada dos elementos do meio físico e socioeconômico permitiu as seguintes conclusões: os Latossolos Vermelhos textura argilosa 


\section{ANAP Brasil ISSN 1904-3240 v. 8, n. 12}

\section{REVISTA CIENTÍFICA 2015}

estão presentes nos topos e nas médias/altas vertentes em relevo plano a suave ondulado onde a suscetibilidade à erosão é ligeira e apresentam boa fertilidade. O uso predominante desses solos é a lavoura temporária (soja, milho e trigo). O Nitossolo Vermelho possui alta fertilidade e encontra-se nas médias/baixas e baixas vertentes onde o relevo varia de ondulado a suave ondulado. A suscetibilidade à erosão é moderada a moderada/forte, e o uso predominante é a lavoura temporária, com pequenas porções próximas dos cursos dos rios ocupadas por pastagens e áreas de preservação permanente.

Foi observada uma zona de transição com presença de Latossolo Vermelho textura média, com Nitossolo Vermelho de textura argilosa e Latossolo Vermelho textura argilosa, sendo utilizadas para o cultivo de lavouras, em virtude da demanda do mercado, embora sejam observadas algumas áreas com pastagem.

O Latossolo de textura média está presente nos topos e nas médias altas vertentes, em relevo plano a suave ondulado, onde a suscetibilidade à erosão é moderada e o Argissolo nas áreas de média baixa e baixa vertente, em relevo ondulado e suave ondulado, onde a suscetibilidade à erosão varia de forte a moderada/forte, mas ambos os solos são de baixa fertilidade natural e o uso predominante é a cana-de-açúcar, pastagem e a criação de aves, essa última surge como uma nova alternativa de renda em solos menos produtivos.

O Neossolo Regolítico eutrófico textura argilosa, também derivado do basalto, encontra-se no topo, média alta, média baixa e baixa vertente, em relevo ondulado e forte ondulado onde a suscetibilidade à erosão varia de forte a muito forte. $O$ uso predominante desse solo é a pastagem e algumas reservas florestais.

Portanto, pode-se observar que toda a diversidade econômica encontrada no município de Iguaraçu (lavoura temporária, lavoura cana-deaçúcar, avicultura e gado) se distribui de acordo com as condições geoecológicas, particularmente, com a geologia, classes de solos, forma de relevo e suscetibilidade à erosão. 


\section{ANAP

\section{REVISTA CIENTÍFICA 2015}

\section{REFERÊNCIAS}

EMBRAPA. Centro Nacional de Pesquisa em Solos. Sistema Brasileiro de Classificação de Solos (SiBCS), 2006.

EMBRAPA. Serviço Nacional de Levantamento e Conservação de Solos. Critérios para distinção de classes de solos e de fases de unidades de mapeamento: normas em uso pelo SNLCS. Rio de Janeiro, 1988. 68p. (EMBRAPA-SNLCS. Documentos, 11).

IAPAR, Erosão Inventário de áreas críticas no Noroeste do Paraná, IAPAR, Fundação Institucional Agronômico do Paraná, Boletim técnico n 23, Londrina PR, 1988, 18 p.

IAPAR, Manejo de solos de baixa aptidão agrícola no Centro-Sul do Paraná, Instituto Agronômico do Paraná, Londrina, Paraná, 1994. p.112. ilust. Circular, 84.

IBGE. Manual Técnico de Uso da Terra. Instituto Brasileiro de Geografia e Estatística, 2ed, Rio de Janeiro, 2006.

IBGE. Manual Técnico de Pedologia. Instituto Brasileiro de Geografia e Estatística, 2ed, Rio de Janeiro, 2007.

MINEROPAR, Atlas Geológico do Estado do Paraná, Curitiba, 2001,116p. 